\section{Determination of the Absolute Concentration of Deuterium in Thames River Water}

THE deuterium content of natural waters has hitherto been determined either by accurate density measurements or by a mass spectrometer, absolute values being obtained by intercomparison with standard samples of known absolute deuterium concentration prepared from deuterium-free water. However, density measurements are complicated by variations in the concentrations of the more abundant oxygen-17 and oxygen-18 isotopes, and the preparation of deuterium-free water is a long procedure. These complications can be eliminated by the following simple method, using only a mass spectrometer.

A number of standard water samples are first prepared from mixtures of the natural water and pure heavy water, giving different known excess concentrations, $\Delta C$, above the unknown absolute concentration, $C_{0}$, of deuterium in the natural water. The values of $\Delta C / C_{0}$ are then directly determined by the mass spectrometer, since

$$
\frac{\left(\mathrm{HD} / \mathrm{H}_{2}\right) \mathrm{std} .}{\left(\mathrm{HD} / \mathrm{H}_{2}\right) \text { nat. }}=1+\left(\Delta C / C_{0}\right)
$$

where both $C_{0}$ and $\Delta C \ll 1$. Hence, by plotting $\Delta C / C_{0}$ against $\Delta C$, a straight line passing through the origin should be obtained, the reciprocal of the slope giving the value of $C_{0}$.

This method was used for determining the absolute concentration of deuterium in Thames water, sampled. in August 1953, no previous mass spectrometer determinations having been made for any British fresh waters. Three standard water samples were prepared by weighing, using heavy water containing $99 \cdot 73 \pm 0.01$ per cent deuterium and only 0.02 per cent oxygen-18 in excess of its natural concentration of 0.20 per cent. Gas samples were prepared from these and from natural water by reduction ${ }^{1}$ of 25-mgm. quantities over uranium metal turnings at $500^{\circ} \mathrm{C}$. The molecular isotope abundance ratio, $\mathrm{HD} / \mathrm{H}_{2}$, for each of the standard samples was compared with that of the natural sample using a mass spectrometer of high stability developed from a design of Nier's ${ }^{2}$. The results and mean deviations are shown in Table 1 and Fig. 1.

Table 1

\begin{tabular}{|c|c|c|c|}
\multicolumn{2}{|c|}{$C_{0}=0.0152 \pm 0.0003$ per cent deuterium } \\
\hline Sample & 1 & 2 & 3 \\
\hline$\Delta C$ (per cent) & 0.005800 & 0.01160 & 0.01740 \\
\hline$\left(\Delta C / C_{0}\right)$ & $0.384 \pm 0.004$ & $0.761 \pm 0.002$ & $1.140 \pm 0.006$ \\
\hline
\end{tabular}

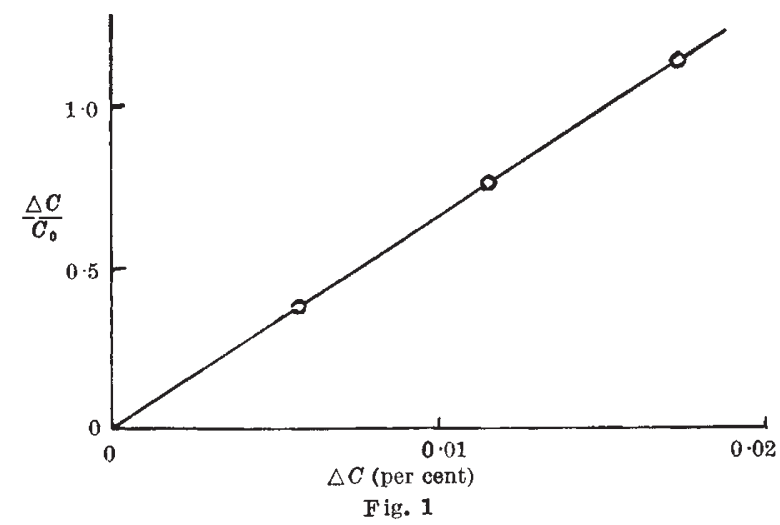

The error quoted for $C_{0}$ includes the maximum possible systematic error which could have been introduced if the resistors used to measure the ion beams had not obeyed Ohm's law. Separate measurements showed that this error could not have exceeded \pm 1 per cent of $\triangle C / C_{0}$. The normal procedure for correcting for the formation of tritium ions was used in which the effect, noted by Friedman ${ }^{3}$, of a departure from the assumed linear relationship between the $\mathrm{HD} / \mathrm{H}_{2}$ ratios and the $\mathrm{H}_{3}$ beam intensity at low values of the latter did not occur and was not therefore a source of error. The total measured memory effect between samples was -1 per cent of $\Delta C / C_{0}$, for which the above results have been corrected.

Friedman's ${ }^{3}$ recent survey of absolute deuterium eoncentrations, with a precision of \pm 0.00002 per cent and absolute to within \pm 0.0002 per cent, included values ranging from $0 \cdot 0133-0 \cdot 0154$ per cent for a wide variety of American fresh waters, and $0.0153-0.0156$ per cent for various ocean waters. Thus our absolute value for Thames water lies at the high end of the American freshwater range and near the less variable ocean values. This may be attributed to the fact that the bulk of the rainfall entering the Thames is only an initial condensed fraction of the water vapour carried inland by the prevailing Atlantic winds. The resulting deuterium enrichment on condensation then approximately cancels the original depletion (about 9 per cent at $10^{\circ} \mathrm{C}$.) occurring on evaporation from the Atlantic, although there may be some further depletion before being carried inland. In contrast, for a large land mass like the United States, where a much higher proportion of the water vapour carried inland is ultimately condensed, freshwater concentrations extend well below the ocean values.

\section{G. R. CLARKE \\ W. H. DEnToN \\ P. REYNOLDS}

Atomic Energy Research Establishment, Harwell, Berks. June 15.

${ }^{1}$ Bigeleisen, J., Perlman, M. C., and Prosser, H. C., Anal. Chem., 24, 1356 (1952).

${ }^{2}$ Nier, A. O., Inghram, M. G., Stevens, C. M., and Rustad, B., "Mass Spectrometer for Routine Hydrogen Isotope Analysis", A.E.C.D., 2806 , and Supp. No. 1.

s Friedman, I., Geochimica et Cosmochimica Acta, 4, Nos. 1/2, 89 (1953).

\section{A Deep Sounding from the Southern Hemisphere}

IT is well known that the great trenches of the Western Pacific represent larger vertical departures from the level surface of the geoid than even the Himalayas. But our knowledge of the shape of the ocean floor is still so fragmentary that the question as to which trench is the deepest has received several different answers within the past two decades. The Mindanao Trench east of the Philippines was long believed to contain the greatest oceanic depth; but for a few years prior to 1950 many authorities considered that the U.S.S. Ramapo soundings in the Japan Trench were the deepest yet recorded. In that year Hess and Buell ${ }^{1}$ re-examined the data and concluded that the sounding of $5,740 \pm 50$ fathoms obtained in the Mindana Trench by the U.S.S. Cape Johnson during the Second World War represented the greatest depth. H.M.S. Challenger in 1951 made still deeper soundings in the Marianas Trench east of Guam. These were reported by Carruthers and Lawford ${ }^{2}$, and later Gaskell, Swallow and Ritchie ${ }^{3}$ 